\title{
Application of Agro-Biological Concepts for Measuring Stability in Fababean (Vicia faba)
}

\author{
H. L. Raiger* and N.K. Jajoriya
}

National Bureau of Plant Genetic Resources, Pusa Campus, New Delhi - 110 012, India

*Corresponding author

A B S T R A C T

\section{Ke ywords \\ Fababean, stability, $\mathrm{G} \times \mathrm{E}$ interaction, biological parameters, agronomic performance \\ Article Info \\ Accepted: \\ 12 February 2020 \\ Available Online: \\ 10 March 2020}

Phenotypic stability was studied in 12 fababean genotypes grown at six locations in northern plains of India. Significant genotype $(G) \times$ environment (E) interactions were observed for grain yield. Among the linear and non-linear components of $\mathrm{G} \times \mathrm{E}$ interaction, linear component was predominant for yield of fababean. Fababean genotypes namely, HB 115, HB 123, HB 131, HB 186 and HB 193 were found to be stable based on agronomic parameters of stability whereas genotypes HB 43, HB 123 and HB 131 were observed to be more stable when biological parameters of stability were taken into consideration. However, only two genotypes viz., HB 123 and HB 131 were found to be stable under both agronomic and biological parameters of stability. Hence, both agronomic as well as biological parameters should be applied for identification of stable genotypes in fababean.

\section{Introduction}

Fababean is an important grain legume crop with immense potential for diversified uses. Fababean seed is used for both human as well as livestock food. Large seeded cultivars of fababean are used as vegetable and frequently used for canning. Its green pods are also used as vegetable in some areas. High grain yield of fababean coupled with high protein content makes it one of the promising crops for food and nutritional security. However, this crop has not yet attained the status of a major crop because of its extremely variable seed yield. Stability of performance of genotypes over environments is, therefore, a pre-requisite for commercial popularization of a crop under sustainable production system.

Hence, the present investigation on phenotypic stability was conducted to identify suitable genotypes across the environment. This will also be helpful in designing the appropriate strategies for increasing the area 
under cultivation of fababean. Depending upon the final goal of the breeder and the character under consideration, two criteria of stability i.e. biological and agronomic concepts (Becker, H.C. 1981a), can be utilized. These are also known as static and dynamic concepts, respectively (Leon, J. 1985). Under the biological concept a stable genotype is one whose phenotype $\left(y_{i j}\right)$ shows little deviation from the expected character level $\left(\bar{y}_{i}\right)$ when the genotype is performancetested over a number of environments. This type of yield stability is analogous to the concept of genetic homeostasis (Lerner, I.M. 1954). In view of the restriction regarding constant performance level at the different environments considered, this concept is also termed the static concept of stability.

The biological concept as applied to a character like grain yield would mean that a stable genotype will perform well under adverse environments but not so well under favourable environments. But with increased level of inputs, improved technology, etc. the breeder would prefer a genotype whose performance in a particular environment is at an expected level depending on the level of productivity of the location as measured by the average productivity of all the genotypes grown in that environment. In other words he is interested in a variety which does not show any genotype-environment interaction, i.e. $\left(y_{i j}-\bar{y}_{i}-\bar{y}_{j}+\bar{y}\right) \cong 0$, for all $i$. This concept which permits a predictable response in each environment and no deviation from the amount predicted is known as the agronomic or dynamic concept of stability (Wricke, G. 1962).

\section{Materials and Methods}

For the present study, the data recorded on grain yield under advance of the fababean varietal trial of All India Coordinated
Research Project on Underutilized Crops were used. The trial comprised of 12 entries including a check, was carried-out at six locations, namely, Faizabad, Delhi, Hisar, Ranchi, Ludhiana and Ambikapur in Randomized Block Design (RBD) with three replications in Rabi 2001-02.

Seven widely used parametric stability measures and their underlying stability concepts (Table 1) were used for measuring the stability in fababean.

\section{Results and Discussion}

The mean seed yield of all the 12 test entries has been recorded. It is apparent from the data that a wide range could be recorded in grain yield across the locations.

Significant difference in squares (Table 2) among genotypes (G) and environments (E) for grain yield indicated the differences among genotypes and environments. The significant mean squares due to $G \times E$ interaction indicated differential behaviour of genotypes across environments (locations). Among the linear and non-linear components, linear component was predominant. The positive and negative values of environmental index (Table 3) indicated the presence of favourable and unfavourable situations, which is an essential requirement to carry-out stability analysis.

According to Eberhart and Russell (Eberhart, S.A. and Russell, W.A. 1966), a stable genotype is one which shows high mean yield $(\bar{x})$, regression coefficient $\left(b_{i}\right)$ around unity, near zero mean square deviation from regression $\left(s_{d_{i}}^{2}\right)$. However, there are some statistical lacunae in the Eberhart and Russell approach. The major drawback include a conseuqnce of non-independent measure of environmental index $\left(e_{j}\right)$, the joint regression 
[Env (linear)] sum of squares with $(s-1)$ degrees of freedom. Another trouble with this approach is that the comparison of linear component of interaction with deviations from regression assumes the homogeneity of individual deviation. Testing the individual deviation against $s_{e}^{2}$, it was found that $s_{d_{i}}^{2}$ for the genotypes and HB 207 were significantly different from zero. Also, low value of nonlinear interaction is solely present due to the genotypic $\times$ environment interaction. As regards the coefficient of overall regression $\frac{\sum b_{i}}{t}=1.00$

Based on values of $s_{d_{i}}^{2}$, HB 115, HB 123, HB 131, HB 193 and HB 186 are more suitable for all environments. The variance ratio $\left(\frac{\sigma^{2}}{s_{e}^{2}}\right)$

can be tested for significance using $\mathrm{F}$ distribution. The test reveals that the variance ratios are significant only for genotype $\mathrm{HB}$ 43, HB 180, HB 192 and HB 207, rest of the genotypes are stable.

Table.1 Common stability measures and their underlying stability concepts

\begin{tabular}{|l|c|l|}
\hline Stability measured & $\begin{array}{c}\text { Symbo } \\
\mathbf{l}\end{array}$ & $\begin{array}{l}\text { Stability concept } \\
\text { involved }\end{array}$ \\
\hline Environmental coefficient of variation (Lerner, I.M. 1954) & $\mathrm{cv}$ & Biological \\
\hline Hanson's stability measure (Hanson, W.D. 1964) & $\hat{D}_{(i .)}^{2}$ & Agronomic \\
\hline Ecovalence (Wricke, G. 1962) & $W_{i}$ & Agronomic \\
\hline Regression coefficient (Eberhart and Russell, 1966) & $b_{i}$ & Biological/Agronomic \\
\hline Deviation mean square (Eberhart, and Russell, 1966) & $s_{d_{i}}^{2}$ & Agronomic \\
\hline Coefficient of determination (Pinthus, M.J. 1973) & $r_{i}^{2}$ & Agronomic \\
\hline Stability variance (Shukla, G.K. 1974) & $\hat{\sigma}_{i}^{2}$ & Agronomic \\
\hline
\end{tabular}

Table.2 Pooled analysis of variance for grain yield of fababean over 6 environments

\begin{tabular}{|l|c|c|c|}
\hline Source & d.f. & M.S. & Variance \\
\hline Genotype & 11 & $42.63^{* *}$ & 4.49 \\
\hline Within genotype & 60 & 247.96 & \\
\hline Environment linear & 1 & 1180.57 & \\
\hline G $\times$ E (Linear) & 11 & $1203.78 \# \# * *$ & 493.75 \\
\hline Pooled deviation & 48 & 9.42 & 3.89 \\
\hline Average error & 132 & 2.44 & \\
\hline
\end{tabular}


Table.3 Different stability parameters for seed yield of 12 genotypes of fababean

\begin{tabular}{|c|c|c|c|c|c|c|c|c|c|}
\hline S.No. & Genotypes & $\overline{\mathbf{x}}$ & cv & $\boldsymbol{D}_{(i)}$ & $W_{i}$ & $b_{i}$ & $\mathrm{~s}_{\mathrm{d}_{\mathrm{i}}}^{2}$ & $r_{i}^{2}$ & $\sigma_{i}^{2}$ \\
\hline 1. & HB 43 & 28.67 & 55.69 & 15.23 & 55.28 & 1.02 & $11.30 *$ & 0.95 & $4.85^{* *}$ \\
\hline 2. & HB 115 & 25.62 & 60.39 & 13.31 & 13.75 & 1.00 & 1.00 & 0.99 & 0.32 \\
\hline 3. & HB 123 & 26.44 & 58.74 & 13.56 & 19.41 & 1.00 & 2.41 & 0.98 & 0.94 \\
\hline 4. & HB 131 & 26.95 & 56.47 & 12.79 & 13.41 & 0.98 & 1.34 & 0.98 & 0.50 \\
\hline 5. & HB 180 & 27.07 & 68.29 & 20.12 & 73.94 & 1.19 & $5.10 * *$ & 0.98 & $6.88 * *$ \\
\hline 6. & HB 186 & 23.60 & 59.52 & 10.38 & 27.71 & 0.91 & 1.89 & 0.98 & 1.85 \\
\hline 7. & HB 192 & 18.25 & 54.94 & 5.99 & 198.58 & 0.63 & $6.55 * *$ & 0.91 & $20.41 *$ \\
\hline 8. & HB 193 & 25.80 & 68.96 & 18.32 & 38.39 & 1.15 & 0.16 & 0.99 & 3.01 \\
\hline 9. & HB 207 & 23.03 & 74.23 & 19.54 & 182.51 & 1.04 & $42.66^{*}$ & 0.85 & $18.71 *$ \\
\hline 10. & BSH 9 & 24.58 & 66.52 & 15.70 & 41.20 & 1.05 & 7.16 & 0.96 & 3.12 \\
\hline 11. & BSH 42 & 26.15 & 62.15 & 14.81 & 8.30 & 1.06 & -1.28 & 1.00 & -0.27 \\
\hline 12. & $\begin{array}{l}\text { VH 82-1 } \\
\text { (Check) }\end{array}$ & 24.19 & 52.24 & 13.05 & 36.44 & 0.97 & 6.36 & 0.96 & 2.80 \\
\hline
\end{tabular}

Significant at $1 \%$ level $* *$ Significant at $5 \%$ level

Table.4 Stable genotypes depending on concept involved

\begin{tabular}{|c|c|c|c|}
\hline $\begin{array}{l}\text { Stability } \\
\text { concept } \\
\text { involve }\end{array}$ & $\begin{array}{c}\text { Stability } \\
\text { parameters } \\
\text { used }\end{array}$ & Stable genotype & $\begin{array}{l}\text { Stable genotype } \\
\text { based on both } \\
\text { biological and } \\
\text { agronomical } \\
\text { concepts }\end{array}$ \\
\hline \multirow[t]{5}{*}{ Agronomic } & $D_{i}^{2}$ & HB 192, HB 186, HB 115, HB 123, HB 131 & \multirow[t]{7}{*}{ HB 131, HB 123} \\
\hline & $W_{i}^{2}$ & BSH 42, HB 131, HB 115, HB 123 & \\
\hline & $s_{d_{i}}^{2}$ & HB 193, HB 186, HB 131, HB 123 & \\
\hline & $\sigma_{i}^{2}$ & HB 115, HB 123, HB 131, HB 186 & \\
\hline & $r_{i}^{2}$ & $\begin{array}{l}\text { BSH } 42 \text {, HB 193, HB 115, HB 123, HB 131, } \\
\text { HB } 186\end{array}$ & \\
\hline \multirow[t]{2}{*}{ Biological } & $\mathrm{cv}$ & HB 192, HB 43, HB 123, HB 131 & \\
\hline & $b_{i}$ & HB 131, HB 123, HB 115, HB 43 & \\
\hline
\end{tabular}


The estimates of $\sigma^{2}, D_{i}$ and $W_{i}$ can be used for making the genotypes according to this yield stability standing. Taking mean yield of the varieties also into account for taking these parameters, varieties HB 115, HB 123, HB 131, HB 186, HB 193 and BSH 9 are adapted to all environments. According to Pinthus $r_{i}^{2}$ (Pinthus, M.J. 1973) for ranking, genotype, high value of $r_{i}^{2}$ are regarded as being desirable. Thus, genotype BSH 9, HB 115, HB 131, HB 123, HB 186 and HB 193 are most suitable to all environments. Now the stable genotypes can be classified based on biological and agronomical concept (Table 4).

Fababean genotypes HB 115, HB 123, HB 131, HB 186 and HB 193 were found to be stable based on agronomic parameters of stability whereas genotypes HB 43, HB 123 and HB 131 were observed to be more stable when biological parameters of stability were taken into consideration and only HB 123 and HB 131 were recorded to be stable under both agronomic and biological parameters of stability. Hence, both agronomic as well as biological parameters should be applied for identification of stable genotypes in fababean.

\section{References}

Becker, H.C. 1981a. Correlations among some statistical measures of phenotypic stability. Euphytica, 30: 835-840.

Eberhart, S.A. and Russell, W.A. 1966. Stability parameters for comparing varieties. Crop Science, 6: 36-40.

Hanson, W.D. 1964. Genotype-environment interaction concepts for field experimental. Biometric. 20: 540-552.

Leon, J. 1985. Beitrage zur Erfassung der phanotypischen Stabilitat unter besonderer Berucksichtigung unterschiedlicher Heterogenitats-und Heterozygotiergrade sowie einer zusammenfassenden Beurteilung von Ertragshohe and Ertragessicheit. Dissertation, Christian-AlbrechtsUniversitat Kiel.

Lerner, I.M. 1954. Genetic homeostasis. Oliver and Boyd, London.

Pinthus, M.J. 1973. Estimate of genotypic value. A proposed method. Euphytica, 22: 121-123.

Shukla, G.K. 1974. Some statistical aspects of partitioning genotype-environmental components of variability. Heredity, 29: 237-245.

Wricke, G. 1962. Ober cine Methode zur Brtasiung dar Okologischen streubreite in Feld versuchen. Z. Pflzucht. 47: 9296.

\section{How to cite this article:}

Raiger. H. L. and Jajoriya. N.K. 2020. Application of Agro-Biological Concepts for Measuring Stability in Fababean (Vicia faba). Int.J.Curr.Microbiol.App.Sci. 9(03): 1556-1560. doi: https://doi.org/10.20546/ijcmas.2020.903.182 